\title{
Palaeotidal atlas of the UK for the last 10,000 years
}

\section{Jon Hill ${ }^{1}$}

\section{${ }^{1}$ Department of Environment and Geography, University of York. jon.hill@york.ac.uk}

Keywords: $\quad$ sea level, modelling, tides

This manuscript is a preprint and has been submitted for publication in Open Quaternary. Please note that this manuscript has yet to undergo peer review. Subsequent versions of this manuscript may have slightly different content. If accepted, the final version of this manuscript will be available via the 'Peer-reviewed Publication DOI' link on the right-hand side of this webpage. Please feel free to contact the author.

\section{INTRODUCTION}

During the Holocene the Northwest European continental shelf sea has been transformed due to sea-level rise due to deglaciation of the Fendo-Scandinavian ice sheet. Eustatic sea level has risen some $130 \mathrm{~m}$ meters over the last 16,000 years with the majority of that change taking place between 16,000 and 7,000 years (Lambeck et al., 2014). Not only does the rise vary temporally, but due to isostatic rebound, relative sea level also varies spatially. This legacy is still relevant today as the UK is experiencing differential rates of relative sea level rise with the south of the UK experience much higher rates of relative sea level rise than the north (Shennan et al., 2018).

In order to assess past sea-level changes we need to find evidence of of where the sea level was in the past. This evidence can be geomorphological (e.g. raised beaches), palaeontological or sedimentological (e.g. marine sediments), archaeological (Shennan, 2015). By dating these data, along with accurate measurements of location, the direction sea level is moving in and height above/below modern mean water height (Shennan, 2015), the data can be terms a Sea Level Index Point (SLIP). However, most SLIPS are data within the tidal range; that is they represent some measure of water level, but not necessary the mean sea level (Hill, 2016; van de 
Plassche, 1986). Therefore, to interpret the SLIP as mean sea level a tidal range is required. Without any other information available, modern tidal ranges are used.

Previous numerical modelling studies have already established that tidal range can change dramatically with changing sea levels. Previous studies have tended to focus on a smaller area, e.g. the Wash or have used relatively coarse resolution of several km over the NW European shelf. On of the first such model that used more than a simple $\mathbf{M}_{2}$ forcing was that of Hinton (1992) which modelled the southern North Sea coast of England using a $3 \mathrm{~km}$ regular grid. Hinton reconstructed palaeobathyemtry simply by reducing or increasing sea level uniformly across the grid. Similar methods were employed by Austin (1991), who also examined the changes in tidal dissipation and tidal fronts. Models have since been developed that made use of GIA models, such as those of Shennan and Horton (2002) and Neill et al. (2010). The inclusion of a GIA model to estimate palaeobathymetric changes take into account the spatial nature of the changes. The most recent NW shelf model was that of Ward et al. (2016) which used a relatively coarse computational mesh of around $4.5 \mathrm{~km}$ (1/24 of a degree) and looked at changes to bed shear stress as well as tidal dynamics. All previous models show substantial changes in the Mean High Water Spring Tides and tidal range due to sea-level changes in the UK.

The result of palaeotidal models can be used to correct SLIPs for palaeo-tidal range. Neill et al. (2010) suggested this to be the case, but noted the inherent circularity of the problem correcting SLIPs alters the GIA model, which in turn alters the palaeobathemtry and then the tidal range estimates. Neill et al. (2010) suggest a procedure whereby some SLIPs are held back from the GIA model used to define the palaeobathmetry of the tidal model to provide a verification-calibration study. Ward et al. (2016) agree that this methodology could be useful and also that higher resolution models are better suited to this as SLIPs are often found near coastlines or in estuaries.

Here, I use multiscale modelling on an unstructured mesh with resolution varying from $20 \mathrm{~km}$ to $1.5 \mathrm{~km}$ around the coastlines, with palaeobathymetry derived from the 2011 GIA modelling of Bradley et al. (2011). This is the first time a multiscale approach has been used in this way and that all model outputs made freely available for further study. Unstructured mesh models have particular advantages when modelling complex coastlines and bathymetries as they avoid the "staircase effect' (Wells et al., 2005a) typically seen in structured mesh models (Fig. 1). Increasing resolution to where it is needed (e.g. coastlines or rapid changes in bathymetry) means that the accuracy of a higher resolution model is obtained whilst minimising computational expense.

In this paper, I outline the details of the model set-up used before validating this model on the modern UK tidal gauge data. I then detail the set up for the palaeotidal models and then present results of the tidal atlas at 1,000 year intervals. Results are shown for a number output parameters including tidal stratification estimates. I conclude by discussing the implications of this study in terms of correcting the European SLIP database and how we could avoid the circularity problem.

\section{METHODS AND MATERIALS}

The palaeotides were calculated using the Fluidity model, which is a highly flexible finite element/control volume modelling framework which allows for the numerical solution of a number of equation sets (Piggott et al., 2008) and has been used in a variety of tidal studies, including both modern and ancient tides on regional and global scales (Wells et al., 2005b,a, 2007, 2010; Martin-Short et al., 2015; Collins et al., 2017, 2018). One of the major advantages of Fluidity is the use of a multiscale mesh, which can resolve fine-scale details even in a regional setting using resolution down to metre-scale (Martin-Short et al., 2015). 

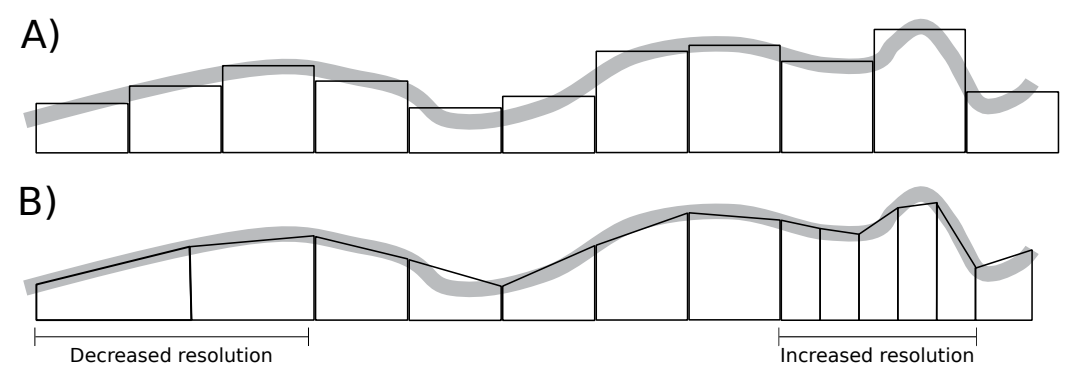

Figure 1. Example of the 'staircase effect" when modelling bathymetry. The thick grey line is the actual bathymetry. In the structured grid model (A) this is represented as a value in a cell, resulting in sharp edges where bathymetry changes more quickly than the mesh size can resolve. In contrast an unstructured grid model can use linear functions within cells (or indeed higher order functions) and change resolution where needed. Unstructured mesh models typically take longer to solve for the same resolution, however.

\section{Fluidity}

Here, the depth-averaged shallow water equations are solved in a rotating reference frame in non-conservative form:

$$
\begin{aligned}
& \frac{\partial u}{\partial t}+u \cdot \nabla u+f u^{T}-\nabla v\left[\nabla u+(\nabla u)^{T}\right]+g \nabla \eta=-c_{b} \frac{\|u\| u}{H}, \\
& \frac{\partial \eta}{\partial t}+\nabla \cdot(H u)=0
\end{aligned}
$$

where $u$ is the $2 \mathrm{D}$, depth-averaged velocity vector, $t$ represents time, $\eta$ is the free surface perturbation, $H$ is the total water depth, and $v$ is the kinematic viscosity. The Coriolis term, $f u^{T}$, consists of $u^{T}$, the velocity vector rotated counter-clockwise over $90^{\circ}$, and $f=2 \Omega \sin (\zeta)$, with $\Omega$ the angular frequency of Earth's rotation and $\zeta$ the latitude. The dimensionless friction coefficient $c_{b}$ represent respectively the background bottom drag (assumed constant here).

The equations (1) are discretised on a mixed finite element pair, with a continuous Galerkin, piecewise quadratic formulation for the free surface (P2) and a piecewise linear discontinuous Galerkin approximation $\left(\mathrm{P} 1_{\mathrm{DG}}\right)$ for velocity. The resulting $\mathrm{P} 1_{\mathrm{DG}} \mathrm{P} 2$ velocity/free-surface discretisation has a number of desirable properties described fully in Cotter et al. (2009a,b); Cotter and Ham (2011). In addition to the discretisation of the linear shallow water terms described therein, we employ a standard $\mathrm{P} 1_{\mathrm{DG}}$-discretisation with upwind fluxes and slope limiting for the advection term and the Compact Discontinuous Galerkin scheme Peraire and Persson (2008), for the viscosity term.

A two-level $\theta$ method is employed for time-integration, combined with explicit subcycling for the advection step. Here $\theta=0.53$, which is close to the Crank-Nicolson scheme, and therefore minimises wave dissipation whilst maintaining stability. Two Picard iterations per time-step are used to linearise the nonlinearity in the advection and friction terms. Finally, the linear discretised systems are solved using iterative sparse linear solvers available in PETSc Balay et al. (2018). More details on the spatial and temporal discretisations available in Fluidity are described in Imperial College London AMCG (2015) and Piggott et al. (2008).

\section{Model setup}

The model domain consisted of the entire NW European continental shelf, bordered by coastlines and the Danish Straits (Fig. 2). For present day simulations two coastlines types were modelled. 
One using the high resolution GSHHS coastline dataset (Wessel and Smith, 1996), the other using the $0 \mathrm{~m}$ contour. For each timeslice from $1 \mathrm{ka}$ to $10 \mathrm{ka}$, modern bathymetry derived from GEBCO 2014 (Weatherall et al., 2015) was adjusted according to the glacio-isotatic adjustment (GIA) model of Bradley et al. (2011) to create a palaeobathymetry. For each palaeobathymetry, a coastline derived from the $0 \mathrm{~m}$ contour was created, which served as a numerical boundary. This was trimmed to meet the western boundary and the boundary at the Denmark Straits. The mesh resolution varied with highest resolution along coastlines (1.5 km triangles), $3 \mathrm{~km}$ along other boundaries and $25 \mathrm{~km}$ between 50 and $100 \mathrm{~km}$ away from a boundary. In addition, a mesh metric based on idealised wave celerity increased resolution in deeper water where the tidal wave moves quickest (Lambrechts et al., 2008) via:

$$
50000.0 * \sqrt{\frac{10.0}{h}}
$$

where $h$ is the water depth. All points on the coastlines and boundaries were joined using a B-spline curve to produce a smooth boundary for the final mesh. All meshes were constructed in (qmesh) (Avdis et al., 2018).

The coastlines and sea bed were set to no-normal flow with a Manning quadratic drag formulation applied with a drag coefficient of 0.025 . The open boundary was forced via free surface using the FES2014 data (Lyard et al., 2006). A short boundary section between coastline and the open boundary was set to a no-slip boundary. Bathymetry was 'dredged' to ensure the minimum water depth was $6 \mathrm{~m}$ to prevent stability issues as the model does not include wetting and drying. Each model was spun up for 30 days, before then being run for another 30 days. The final 30 days were used for all subsequent analyses.

\section{Modern validation}

To assess model performance I compared the model against tide gauge data from around the UK using the two different methods of coastlines generation for the present day ( $0 \mathrm{~m}$ contour and GSHHS). The two modern models were forced along the boundary of the continental shelf using FES 2014 data and eight principle tidal components, $\mathrm{M}_{2}, \mathrm{~S}_{2}, \mathrm{~N}_{2}, \mathrm{~K}_{2}, \mathrm{O}_{1}, \mathrm{Q}_{1}, \mathrm{~K}_{1}$, and $\mathrm{P}_{1}$. The constituents $\mathrm{M}_{2}$ and $\mathrm{S}_{2}$ are the dominant components on the NW European continental shelf. The model was run for a total of 60 days, with the first 30 days considered as 'spin-up'. Free surface height data were then analysed at each tidal gauge location to produce model estimates of $\mathrm{M}_{2}, \mathrm{~S}_{2}, \mathrm{~K}_{1}$, and $\mathrm{O}_{1}$ amplitude and phases and compared to the data from tide gauges. To compare the model against the tide gauges we use the method of Cummins and Thupaki (2017), whereby error, $\xi$ is calculated over the $L$ tidal gauges as:

$$
\begin{aligned}
& \xi=L^{-1} \sum D_{L} \\
& D_{L}=\left[\frac{1}{2}\left(A_{o}^{2}+A_{m}^{2}\right)-A_{o} A_{m} \cos \left(\phi_{o}-\phi_{o}\right)\right]^{\frac{1}{2}}
\end{aligned}
$$

where $A_{m}$ is the modelled amplitude, $A_{o}$ is the observed amplitude, $\phi_{o}$ is the observed phase and $\phi_{m}$ is the modelled phase, at each tidal gauge location. A separate $D$ is calculated for each tidal constituent modelled.

In the modern day, the mode has an error of $0.27-0.39 \mathrm{~cm}$ for $\mathrm{M}_{2}$ and $0.06-0.03 \mathrm{~cm}$ for $\mathrm{S}_{2}$ across 40 or 41 tidal stations ( $0 \mathrm{~m}$ contour or GSHHS coastline respectively), corresponding to a $0.14-0.22$ and $0.06-0.09 \%$ error respectively according to equation 4 . Fluidity appears to slightly under predict the $\mathrm{O}_{1}$ component and over predict the $\mathrm{K}_{1}$ component compared to 


\begin{tabular}{l|l|l|l|l|l}
\hline Model & $\mathrm{M}_{2}$ error & $\mathrm{S}_{2}$ error & $\mathrm{K}_{1}$ error & $\mathrm{O}_{1}$ error & No. Stations \\
GSHHS $(\%)$ & $0.22 \%$ & $0.06 \%$ & $0.07 \%$ & $0.08 \%$ & 41 \\
GSHHS $(\mathrm{cm})$ & 0.39 & 0.03 & 0.07 & 0.08 & 41 \\
Om $(\%)$ & $0.14 \%$ & $0.09 \%$ & $0.82 \%$ & $0.87 \%$ & 40 \\
0m $(\mathrm{cm})$ & 0.27 & 0.06 & 0.08 & 0.08 & 40 \\
\hline
\end{tabular}

tide gauges at higher amplitudes, but the mean semi-diurnal components show an excellent agreement (Fig. 3). Both GSHHS and $0 \mathrm{~m}$ contour derived coastlines perform well overall.

The spatial distribution of the $\mathrm{M}_{2}$ tide and tidal range matches previous modelling studies (Fig. 4). A major control on sediment movement in the NW European shelf sea are tidal currents (Fig 4). Ward et al. (2015) developed a proxy for tidally induced bed shear stress and sediment grain size which attempts to account for additional controls on sediment movement such as waves and storm events. Here, I use this proxy across the whole NW continental shelf to derive grain size estimates from tidal bed shear stress. The modelling results (Fig. 4) show the North Sea grain size as generally coarse sand, fining to very fine sand or less towards Norway. The Celtic Sea is dominated by medium to coarse sand grains, with a ribbon of very coarse send running south from Scotland, through the Isle of Mann towards the Irish coast, before turning more easterly towards Wales. Similarly, the Severn Estuary is also coarse sand. The English channel is also dominated by coarse sands with some Gravel patches on the French coast. The coarse sediment is discontinuous in the easterly direction with patches of medium sand. The results in the Celtic Sea are entirely consistent with Ward et al. (2015) as well as observations by Bockelmann et al. (2018).

\section{PALAEOTIDAL CHANGES}

The $\mathrm{M}_{2}$ tidal component is the dominant component over most of the of NW European continental shelf. At $10 \mathrm{ka}$, an amphidromic point is situated near the palaeo-coastline in the North Sea (Fig. 5). There is a further point further north near Norway. At this time there is a significant reduction in $\mathrm{M}_{2}$ amplitude across the whole seaway. When the land bridge between the UK and mainland Europe forms around $9 \mathrm{ka}$, these points become separated by the land bridge with a single amphidromic point in the English channel and two to the north and south of Dogger Bank respectively. The shallowing of the Dogger Bank area in the southern North Sea creates additional amphidromic points in the area which then precipitates a reduction in $\mathrm{M}_{2}$ amplitude in the English Channel. By the time Dogger Bank becomes emergent at around $8 \mathrm{ka}$, there are complex tidal dynamics in the southern area of the North Sea, with four amphidromic points occurring in the area. At $7 \mathrm{ka}$ the amphidromic points shift towards the modern configuration, with an additional point off the palaeo-coast of Denmark. Between 6 and 0 ka there is no major shift in the amphidromic points and moderate changes in $\mathrm{M}_{2}$ tidal amplitude. There is, however, a minor shift at $4 \mathrm{ka}$. The amphidromic point shifts towards the UK coast from the east of the North Sea at this time. This then reduces the $\mathrm{M}_{2}$ amplitude slightly on the eastern coast of the UK. The driver for this appears to be sea-level change on the north coast of Europe. In the modern, the Severn Estuary and Brittany coast experience high tidal ranges due to the $\mathrm{M}_{2}$ component. The modern North Sea shows amphidromic points (points where phase contours converge) near the Danish coast and in the northern part of the English Channel.

Comparing to previous studies (Neill et al., 2010) and (Ward et al., 2016), the estimates presented here show very similar spatial features as well as absolute values of $\mathbf{M}_{2}$ tidal amplitude and phase. There are minor variations in the location of amphidromic points. The models results here show an additional amphidromal points off the coast of Norway at $10 \mathrm{ka}$ compared to the results of Neill et al. (2010) and (Ward et al., 2016). There is very little difference in the $\mathrm{M}_{2}$ 
amplitudes, however. At 8 ka all models show a complex set of amphidromic points in the southern North Sea, with similar patterns of $\mathrm{M}_{2}$ amplitude.

These changes in the $\mathrm{M}_{2}$ tide causes shifts in tidal range over the time period studies (Fig. 6). The tidal range at $10 \mathrm{ka}$ is much lower than modern day due to the much lower sea level. At $9 \mathrm{ka}$ there is also an increase in tidal range in the Celtic Sea and the Severn Estuary closer to modern values. When the English Channel opens at $8 \mathrm{ka}$ the tidal range is consistent with modern day. The tidal range stays generally consistent to the modern day ranges, apart from a minor change around 4 ka due to the changes in $\mathrm{M}_{2}$ described above. These results mirror those of Neill et al. (2010), which show a rapid reduction of tidal range between 0 and $10 \mathrm{ka}$ with most of that change taking place at some point between $6 \mathrm{ka}$ and $10 \mathrm{ka}$. However, the tidal range estimates presented here at $10 \mathrm{ka}$ are slightly lower than that of Neill et al. (2010).

\section{Tidal mixing}

Tidal mixing occurs when the tidal currents are strong enough to induce turbulence via shear on the sea bed. There is therefore a relationship between water depth, tidal velocity and mixing in the water column which can be described using the Hunter-Simpson parameter, $H_{s}$,

$$
H_{s}=\log _{10} \frac{h}{u^{3}}
$$

where $h$ is the water depth $(\mathrm{m})$ and $u$ is the mean of tidal velocity magnitude $(\mathrm{m} / \mathrm{s}$ ) (Simpson and Hunter, 1974). Where tidal mixing occurs, it can flux nutrients from depth into the photic zone, thereby increasing primary productivity. This mixing occurs in the summer months when the solar radiation is sufficiently strong to induce stratification. Simpson and Hunter (1974) cite a value of between 1.5 and 2.0 for eq. 5 for where the transition between mixed and stratified water occurs; the tidal front, which has been confirmed with observations in the Celtic Sea (Simpson, 1976). Fig. 7 shows the shift in the tidal fronts through time. For the period $10 \mathrm{ka}$ to $7 \mathrm{ka}$ there are widespread mixed areas in the English Channel and Southern North Sea. As sea level rises and becomes similar to modern day these fronts become very similar to those found today (Pingree and Griffiths, 1978), apart from those in the Celtic and Irish Seas. Those fronts develop around $6 \mathrm{ka}$, but are absent at $4-1 \mathrm{ka}$.

\section{Sediment grain size changes}

Changes in sediment grain size largely follow the changes in tidal range (Fig. 8). Generally there is a increase in grain size deposited with time, with fine grains dominating $10 \mathrm{ka}$ and areas becoming dramatically coarser by around $7 \mathrm{ka}$ and then stabilising. The largest changes occur between $10 \mathrm{ka}$ and $7 \mathrm{ka}$ in the English channel. In the modern there are two main areas of very coarse sand deposition in the English channel - on in the narrow seaway between England and France and a large area between the south cost of England and Brittany. These a re largely stable until around $7 \mathrm{ka}$ when the northern patch shrinks whilst the southern area grows. As the English Channel shrinks this southern patch of coarse sediment shifts southwards and eventually decreases in area by $10 \mathrm{ka}$. These results are similar to the tidal bed shear stress calculated by Neill et al. (2010) and Ward et al. (2016), though as with the tidal characteristics there are minor differences in places.

\section{DISCUSSION}

In order to calculate sea level since the Last Glacial Maximum we must first find data that indicate past sea level. These data points are located within a tidal range, however; so in order to place past mean sea level an estimate of past tidal range is required (Shennan, 2015). It is 
important to understand past sea level changes as they relate directly to our estimates of the amount of water sequester by ice sheets during the Last Glacial maximum Clark and Tarasov (2014) and what drives local, regional and global sea level chnage through time (Shennan et al., 2018). Here, I present calculations of past tides of the NW European continental shelf using a finite element model on a multi-scale unstructured mesh. The output of these model simulations are available for other researchers to use.

The tidal characteristics of the European continental shelf show major changes over the past 10,000 years. Most of those changes are associated with the flooding in the southern North Sea from $10 \mathrm{ka}$ to $7 \mathrm{ka}$. From $7 \mathrm{ka}$ to the present day most tidal properties show little variation. The exception to this is at $4 \mathrm{ka}$. At this time the amphrodopmic point for the $\mathrm{M}_{2}$ tide shifts westwards in the southern North Sea moving the corresponding $\mathrm{M}_{2}$ low amplitude with it. This in turn alters tidal range and bed shear stresses in the region. By $3 \mathrm{ka}$ the amphidromic point shifts eastward again, closer to the modern day location.

The shifts in tidal characteristic also have implications in the primary productivity potential of the European shelf. From 10 ka to $7 \mathrm{ka}$ there was a much larger mixed region in the English Channel with associated tidal fronts. These are associated with both shallower water and higher tidal velocities. These fronts would have increased the primary productivity in the region as tidal fronts are a significant percentage of primary productivity in the modern North Sea (Heath and Beare, 2008). This in turn has implications for changes in the biogeochemistry of the North Sea since the Last Glacial Maximum. The present day North Sea is thought to store around 250 MT of Particulate Organic Matter (POC) in the top $10 \mathrm{~cm}$ of sediment (Diesing et al., 2017). Given that the North Atlantic biological pump increased the draw down of carbon during the Last Glacial Maximum (Yu et al., 2019), the increased number of tidal fronts may have had an impact on the POC stored in North Sea sediments.

The model results presented here have a number of limitations. Firstly, the boundary forcing along the continental shelf are derived from modern data with no corrections for global palaeobathymetric changes. This is in contrast to both Neill et al. (2010) and Ward et al. (2016). As the ice sheets in the northern hemisphere grew, they caused changes in the global tidal dynamics. However, the tidal forcing was still strong in this region and broadly comparable to modern tides at least until $10 \mathrm{ka}$, based on previous modelling of global tides (Uehara et al., 2006). Future work will use global tidal models to estimate the tidal boundary forcing on global palaeobathymetries to enable simulations to carried out for reconstructions older than $10 \mathrm{ka}$. Second, the model also lacks inundation of low-laying land due to tidal movement with bathymetry 'dredged' to a minimum of $6 \mathrm{~m}$ water depth. This is a particular problem in estuaries and where most SLIP data are collected. This is similar to both Neill et al. (2010) and Ward et al. (2016) as neither used any wetting and drying algorithms. Whilst the modelled tidal range is not significantly affected the tidal range must instead be taken from a nearby point rather than the precise location of the SLIP. Future work will correct this by adding inundation and increase the spatial resolution around the coast.

The results presented here form only part of the solution for correcting SLIPs for palaeo-tidal range. Once a SLIP is corrected for temporal variations in tidal range, the GIA models then need correcting as they use SLIPs as a constraint, which in turn alters the palaeobathymetry on which the tidal model is based. This presents something of a circular problem. Neill et al. (2010) proposed a methodology whereby some SLIPs are held back from a GIA model to provide a validation-calibration test. However, here, I have used a different palaeobathymetry to Neill et al. (2010) and modern forcing as opposed to palaeotidal estimates. Similarly, Ward et al. (2016) used updated GIA models (same as this work) and a higher model resolution than Neill et al. (2010). Despite these minor differences in boundary forcing, palaeobathymetric reconstructions, and numerical implementations, our estimates of tidal range changes are very similar. This is 
encouraging as it means that tidal range estimates are not overly sensitive to minor variations in tidal forcing or palaeobathymetric estimates. It should therefore be possible to correct SLIPs for tidal range, alter the palaeobathemetry and proceed in an iterative fashion until there are no changes to the tidal estimates - in essence convergence onto our best estimate. Making use of modern numerical techniques such as adjoint solvers would aid in estimating the sensitivity of the tidal model to errors in palaeobathemetry. In turn the sensitivity and error across multiple models and bathymetric estimates could be used in a Bayesian framework similar to that proposed by (Cahill et al., 2016). It would then be possible to account for uncertainty and sensitivity in the SLIP height (including tidal range corrections and the uncertainties within those) and the dating method when deriving sea level estimates.

\section{CONCLUSIONS}

The results published here form a palaeotidal database made freely available for future researchers. The outputs of the model shows significant changes to tidal range, tidal sediment distribution and the tidal components on the NW European shelf area. These data are the first derived on an unstructured mesh model where the mesh resolution of the model can vary spatially, allowing focusing of results in areas of interest (here the coastline) whilst minimising computations time. Unstructured meshes also reproduce bathymetry and coastlines without staircase effects. This is an advance over previous modelling studies that used relatively coarse rectilinear grids.

\section{DATA AVAILABILITY}

Each time slice is available as a NetCDF file which contains tidal amplitudes and phases for each tidal component, maximum and mean bed shear stress and velocity vectors, along with a simple R script to extract nearest data from a list of points. These are available via: DOI: 10.6084/m9.figshare.6993956.

\section{ACKNOWLEDGEMENTS}

This project was undertaken on the Viking Cluster, which is a high performance compute facility provided by the University of York. I am grateful for computational support from the University of York High Performance Computing service, Viking and the Research Computing team. I would also like to thank Graham Rush and Fiona Hibbert (University of York) for commenting on drafts of the manuscript.

\section{REFERENCES}

Austin, R. M. (1991). Modelling Holocene tides on the NW European continental shelf. Terra Nova, 3(3):276-288.

Avdis, A., Candy, A. S., Hill, J., Kramer, S. C., and Piggott, M. D. (2018). Efficient unstructured mesh generation for marine renewable energy applications. Renewable Energy, 116:842-856.

Balay, S., Abhyankar, S., Adams, M. F., Brown, J., Brune, P., Buschelman, K., Dalcin, L., Dener, A., Eijkhout, V., Gropp, W. D., Kaushik, D., Knepley, M. G., May, D. A., McInnes, L. C., Mills, R. T., Munson, T., Rupp, K., Sanan, P., Smith, B. F., Zampini, S., Zhang, H., and Zhang, H. (2018). PETSc users manual. Technical Report ANL-95/11 - Revision 3.9, Argonne National Laboratory.

Bockelmann, F.-D., Puls, W., Kleeberg, U., Müller, D., and Emeis, K.-C. (2018). Mapping mud content and median grain-size of North Sea sediments - A geostatistical approach. Marine geology, 397:60-71. 
Bradley, S. L., Milne, G. A., Shennan, I., and Edwards, R. (2011). An improved glacial isostatic adjustment model for the British Isles. Journal of Quaternary Science, 26(5):541-552.

Cahill, N., Kemp, A. C., Horton, B. P., and Parnell, A. C. (2016). A Bayesian hierarchical model for reconstructing relative sea level: from raw data to rates of change. Climate of the Past, 12(2):525-542.

Clark, P. U. and Tarasov, L. (2014). Closing the sea level budget at the Last Glacial Maximum. Proceedings of the National Academy of Sciences of the United States of America, 111(45):15861-15862.

Collins, D. S., Avdis, A., Allison, P. A., Johnson, H. D., Hill, J., and Piggott, M. D. (2018). Controls on tidal sedimentation and preservation: insights from numerical tidal modelling in the Late Oligocene-Miocene South China Sea, Southeast Asia. Sedimentology.

Collins, D. S., Avdis, A., Allison, P. A., Johnson, H. D., Hill, J., Piggott, M. D., Amir Hassan, M. H., and Damit, A. R. (2017). Tidal dynamics and mangrove carbon sequestration during the Oligo-Miocene in the South China Sea. Nature communications, 8:ncomms 15698.

Cotter, C. J. and Ham, D. A. (2011). Numerical wave propagation for the triangular P1DG-P2 finite element pair. Journal of computational physics, 230(8):2806-2820.

Cotter, C. J., Ham, D. A., and Pain, C. C. (2009a). A mixed discontinuous/continuous finite element pair for shallow-water ocean modelling. Ocean Modelling, 26:86-90.

Cotter, C. J., Ham, D. A., Pain, C. C., and Sebastian, R. (2009b). LBB stability of a mixed Galerkin finite element pair for fluid flow simulations. Journal of computational physics, 228(2):336-348.

Cummins, P. F. and Thupaki, P. (2017). A note on evaluating model tidal currents against observations. Continental shelf research.

Diesing, M., Kröger, S., Parker, R., Jenkins, C., Mason, C., and Weston, K. (2017). Predicting the standing stock of organic carbon in surface sediments of the North-West European continental shelf. Biogeochemistry, 135(1):183-200.

Heath, M. R. and Beare, D. J. (2008). New primary production in northwest European shelf seas, 1960-2003. Marine ecology progress series, 363:183-203.

Hill, D. F. (2016). Spatial and Temporal Variability in Tidal Range: Evidence, Causes, and Effects. Current Climate Change Reports, 2(4):232-241.

Hinton, A. C. (1992). Palaeotidal changes within the area of the Wash during the Holocene. Proceedings of the Geologists' Association. Geologists' Association, 103:259-272.

Imperial College London AMCG (2015). Fluidity manual v4.1.12. figshare.

Lambeck, K., Rouby, H., Purcell, A., Sun, Y., and Sambridge, M. (2014). Sea level and global ice volumes from the Last Glacial Maximum to the Holocene. Proceedings of the National Academy of Sciences of the United States of America, 111(43):15296-15303.

Lambrechts, J., Comblen, R., Legat, V., Geuzaine, C., and Remacle, J.-F. (2008). Multiscale mesh generation on the sphere. Ocean Dynamics, 58(5-6):461-473.

Lyard, F., Lefevre, F., Letellier, T., and Francis, O. (2006). Modelling the global ocean tides: modern insights from FES2004. Ocean Dynamics, 56(5):394-415.

Martin-Short, R., Hill, J., Kramer, S. C., Avdis, A., Allison, P. A., and Piggott, M. D. (2015). Tidal resource extraction in the Pentland Firth, UK: Potential impacts on flow regime and sediment transport in the Inner Sound of Stroma. Renewable Energy, 76(0):596-607.

Neill, S. P., Scourse, J. D., and Uehara, K. (2010). Evolution of bed shear stress distribution over the northwest European shelf seas during the last 12,000 years. Ocean Dynamics, 60(5):1139-1156.

Peraire, J. and Persson, P. (2008). The Compact Discontinuous Galerkin (CDG) Method for Elliptic Problems. SIAM Journal of Scientific Computing, 30(4):1806-1824.

Piggott, M. D., Gorman, G. J., Pain, C. C., Allison, P. A., Candy, A. S., Martin, B. T., and 
Wells, M. R. (2008). A new computational framework for multi-scale ocean modelling based on adapting unstructured meshes. International Journal for Numerical Methods in Fluids, 56(8):1003-1015.

Pingree, R. D. and Griffiths, D. K. (1978). Tidal fronts on the shelf seas around the British Isles. Journal of geophysical research, 83(C9):4615-4622.

Shennan, I. (2015). Handbook of sea-level research: framing research questions. In Shennan, I., Long, A. J., and Horton, B. P., editors, Handbook of Sea-Level Research, volume 113, pages 3-25. John Wiley \& Sons, Ltd, Chichester, UK.

Shennan, I., Bradley, S. L., and Edwards, R. (2018). Relative sea-level changes and crustal movements in Britain and Ireland since the Last Glacial Maximum. Quaternary science reviews, 188:143-159.

Shennan, I. and Horton, B. (2002). Holocene land-and sea-level changes in Great Britain. Journal of Quaternary Science: Published for the Quaternary Research Association, 17(5-6):511-526.

Simpson, J. H. (1976). A boundary front in the summer regime of the Celtic Sea. Estuarine and Coastal Marine Science, 4(1):71-81.

Simpson, J. H. and Hunter, J. R. (1974). Fronts in the Irish Sea. Nature, 250(5465):404-406.

Uehara, K., Scourse, J. D., Horsburgh, K. J., Lambeck, K., and Purcell, A. P. (2006). Tidal evolution of the northwest European shelf seas from the Last Glacial Maximum to the present. Journal of geophysical research, 111(C9):235.

van de Plassche, O., editor (1986). Sea-Level Research. Springer Netherlands, Dordrecht.

Ward, S. L., Neill, S. P., Scourse, J. D., Bradley, S. L., and Uehara, K. (2016). Sensitivity of palaeotidal models of the northwest European shelf seas to glacial isostatic adjustment since the Last Glacial Maximum. Quaternary science reviews, 151:198-211.

Ward, S. L., Neill, S. P., Van Landeghem, K. J. J., and Scourse, J. D. (2015). Classifying seabed sediment type using simulated tidal-induced bed shear stress. Marine geology, 367:94-104.

Weatherall, P., Marks, K. M., Jakobsson, M., Schmitt, T., Tani, S., Arndt, J. E., Rovere, M., Chayes, D., Ferrini, V., and Wigley, R. (2015). A new digital bathymetric model of the world's oceans. Life support \& biosphere science: international journal of earth space, 2(8):331-345.

Wells, M. R., Allison, P. A., Hampson, G. J., Piggott, M. D., and Pain, C. C. (2005a). Modelling ancient tides: the Upper Carboniferous epi-continental seaway of Northwest Europe. Sedimentology, 52(4):715-735.

Wells, M. R., Allison, P. A., Piggott, M. D., Gorman, G. J., Hampson, G. J., Pain, C. C., and Fang, F. (2007). Numerical Modeling of Tides in the Late Pennsylvanian Midcontinent Seaway of North America with Implications for Hydrography and Sedimentation. Journal of Sedimentary Research, 77(10):843-865.

Wells, M. R., Allison, P. A., Piggott, M. D., Hampson, G. J., Pain, C. C., and Gorman, G. J. (2010). Tidal Modeling of an Ancient Tide-Dominated Seaway, Part 1: Model Validation and Application to Global Early Cretaceous (Aptian) Tides. Journal of Sedimentary Research, 80(5):393-410.

Wells, M. R., Allison, P. A., Piggott, M. D., Pain, C. C., Hampson, G. J., and DE Oliviira, C. R. E. (2005b). Large sea, small tides: the Late Carboniferous seaway of NW Europe. Journal of the Geological Society, 162(3):417-420.

Wessel, P. and Smith, W. H. F. (1996). A Global Self-consistent, Hierarchical, High-resolution Shoreline Database. Journal of geophysical research, 101(B4):8741-8743.

Yu, J., Menviel, L., Jin, Z. D., Thornalley, D. J. R., Foster, G. L., Rohling, E. J., McCave, I. N., McManus, J. F., Dai, Y., Ren, H., He, F., Zhang, F., Chen, P. J., and Roberts, A. P. (2019). More efficient North Atlantic carbon pump during the Last Glacial Maximum. Nature communications, 10(1):2170. 


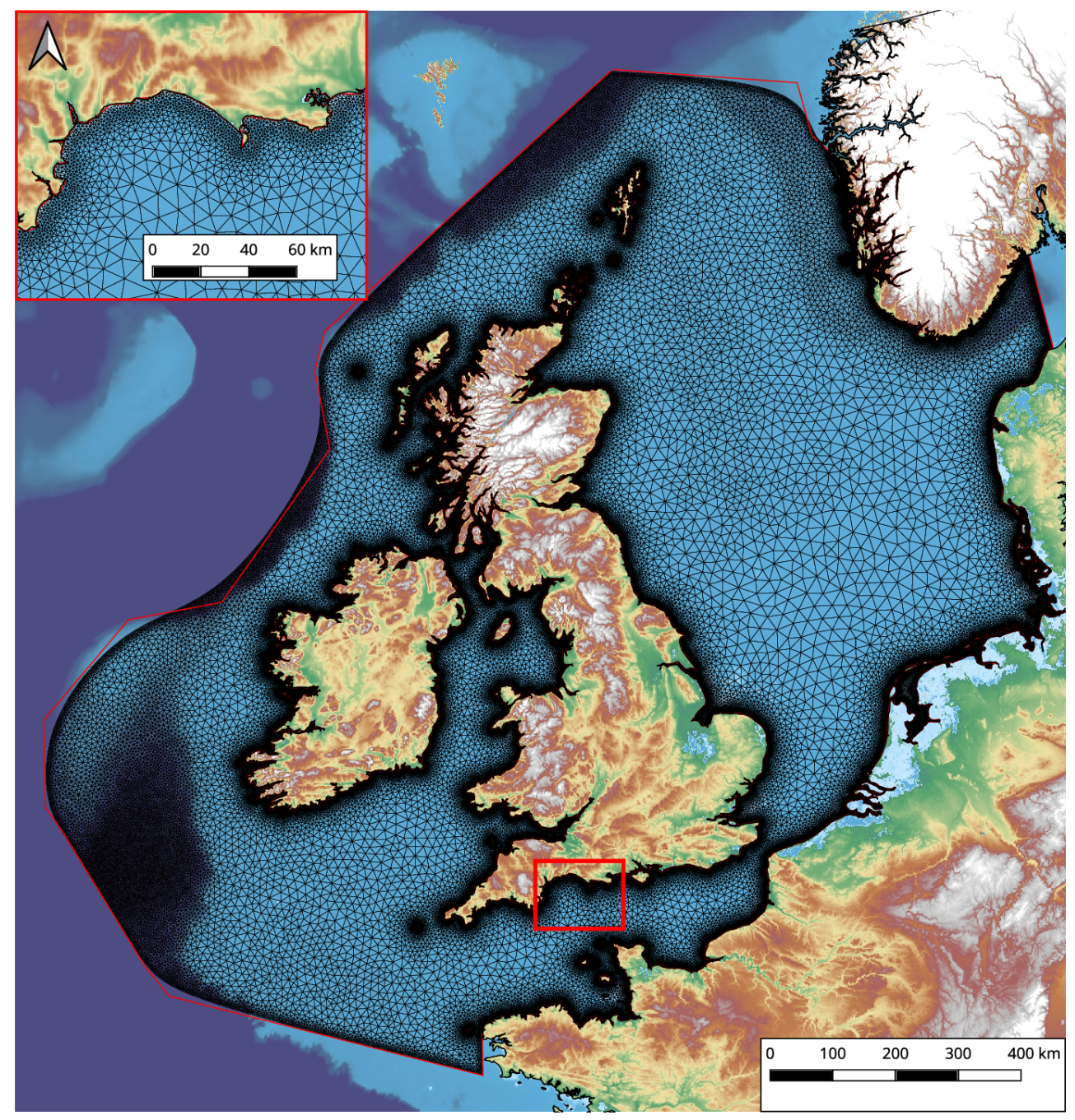

Figure 2. Modern multiscale mesh using GSHHS coastlines (high resolution). Mesh resolution is smallest around coastlines and deeper water. Red line shows the coastline from GSHHS, black is the mesh, and colours show height from the GEBCO bathymetry/topography. A close-up of the south coast of England is shown to highlight the mesh resolution change with respect to the coastline. 
a) 0 m contour coastline

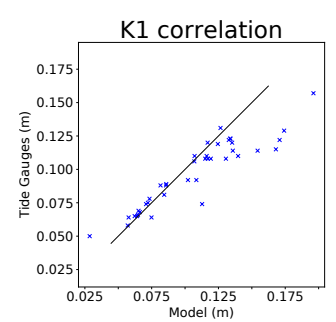

O1 correlation

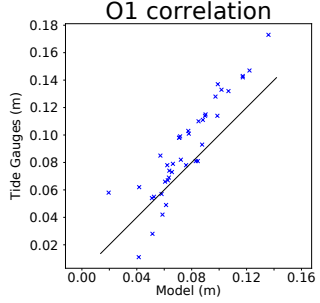

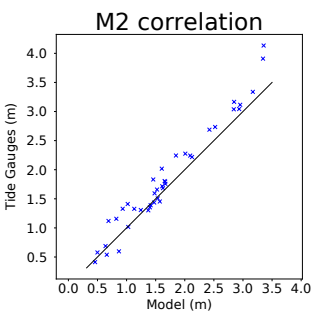

S2 correlation

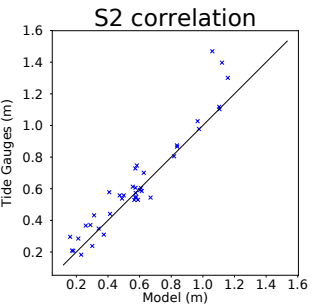

b) GSHHS coastline
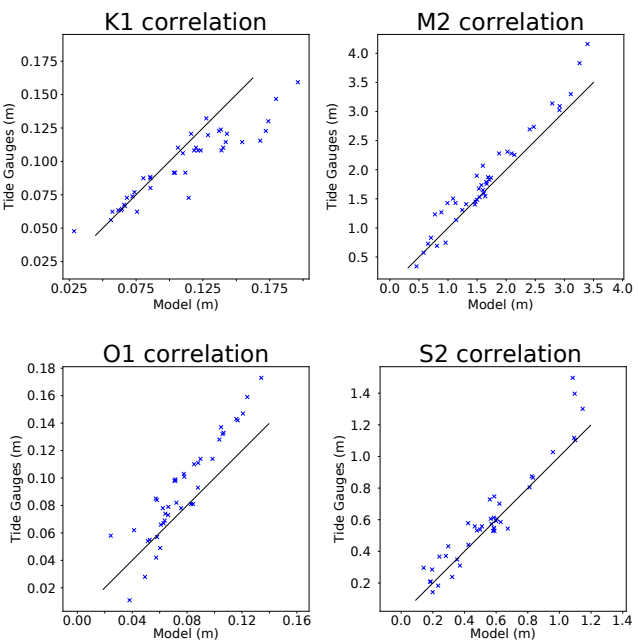

Figure 3. Cross plot of amplitudes generated from Fluidty against tide gauges for four main tidal components using either the $0 \mathrm{~m}$ contour (a) or high resolution GSHHS data (b) as the coastline.
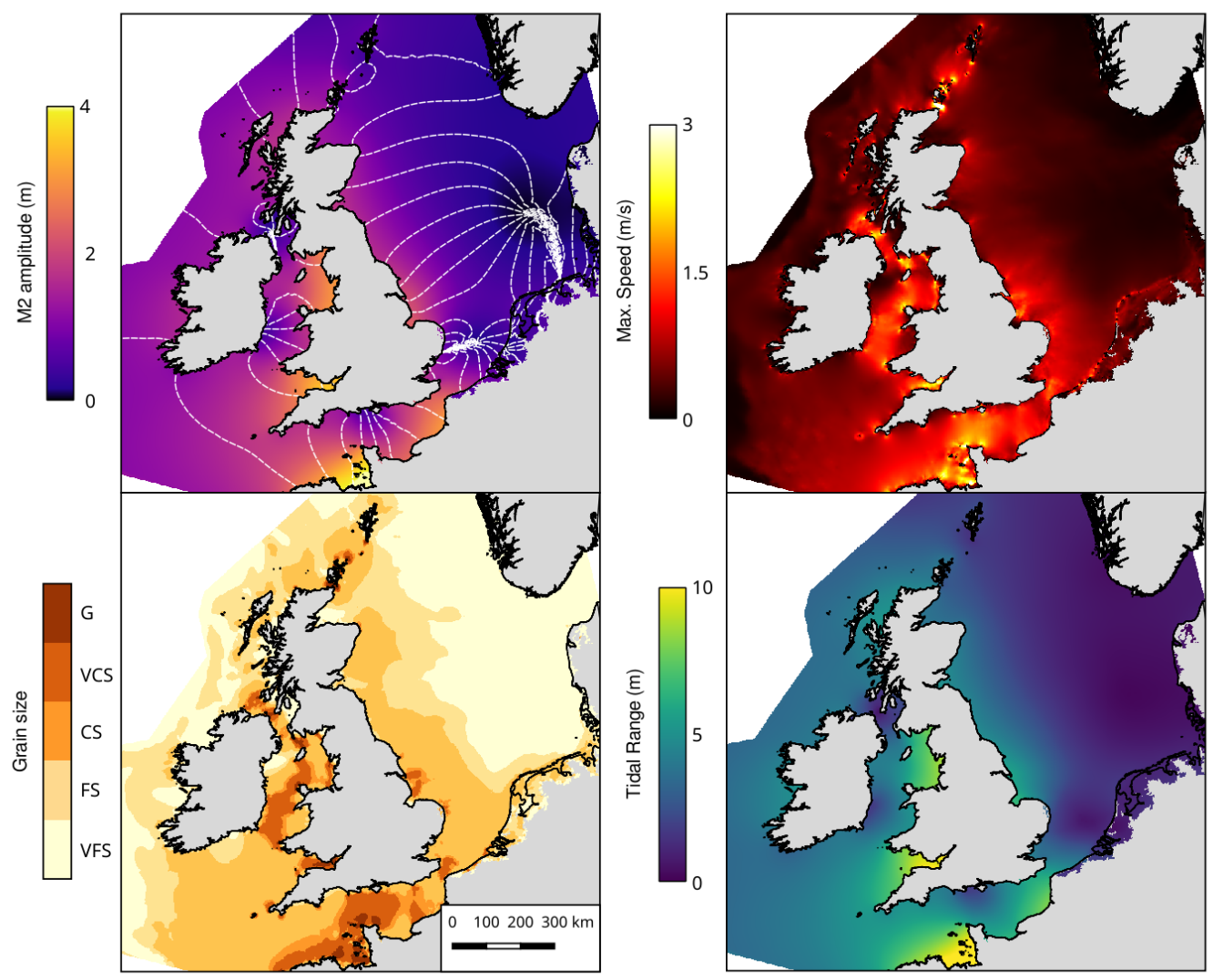

Figure 4. Tidal properties of the present day. Top left: $\mathrm{M}_{2}$ amplitude and phase. Top right: maximum speed over the 30 day simulation. Bottom left: grain size derived from maximum bed shear stress. Bottom right: tidal range. 

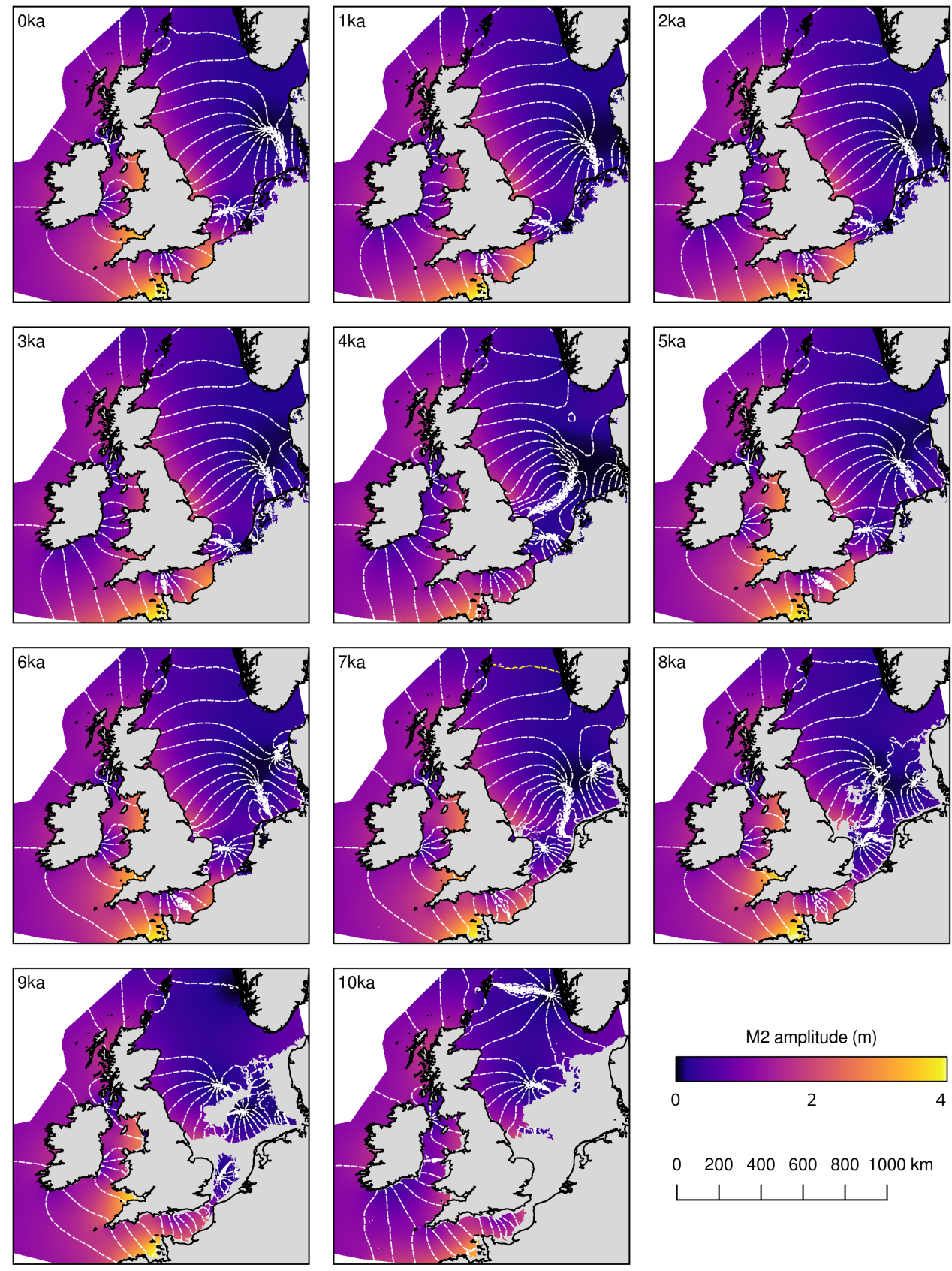

Figure 5. $\mathrm{M}_{2}$ amplitude (colour bar) and phase (contour lines) for each of the time slices from present day to $10 \mathrm{ka}$. Grey shading indicates land and the modern coastline is shown in a think black line. 

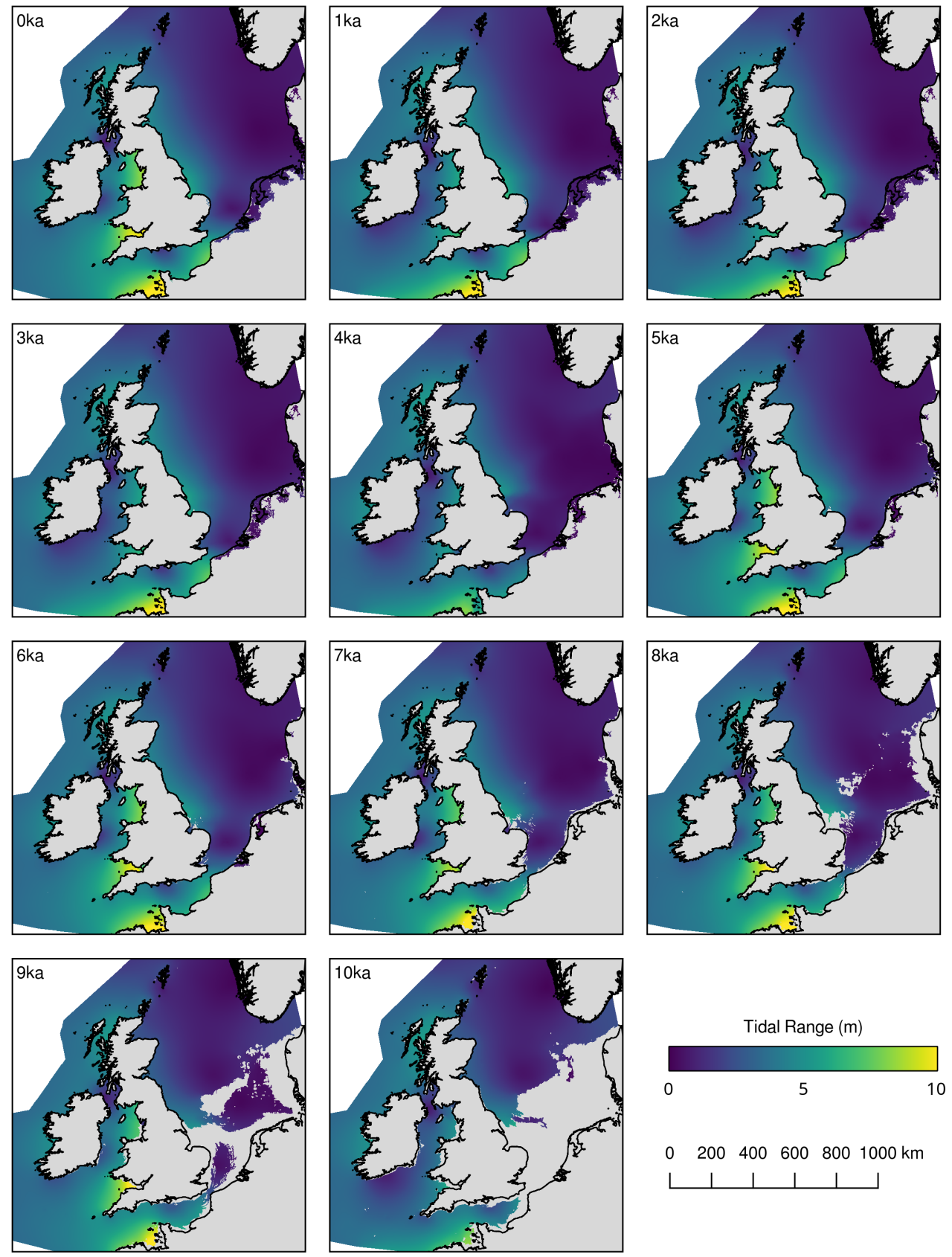

Tidal Range (m)

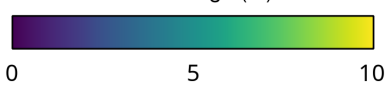

$0 \quad 200 \quad 400 \quad 600 \quad 800 \quad 1000 \mathrm{~km}$

Figure 6. Tidal range in the NW Euopean shelf for each timeslice from present day to $10 \mathrm{ka}$. Add palaeo shorelines. Grey shading indicates land and the modern coastline is shown in a think black line. 

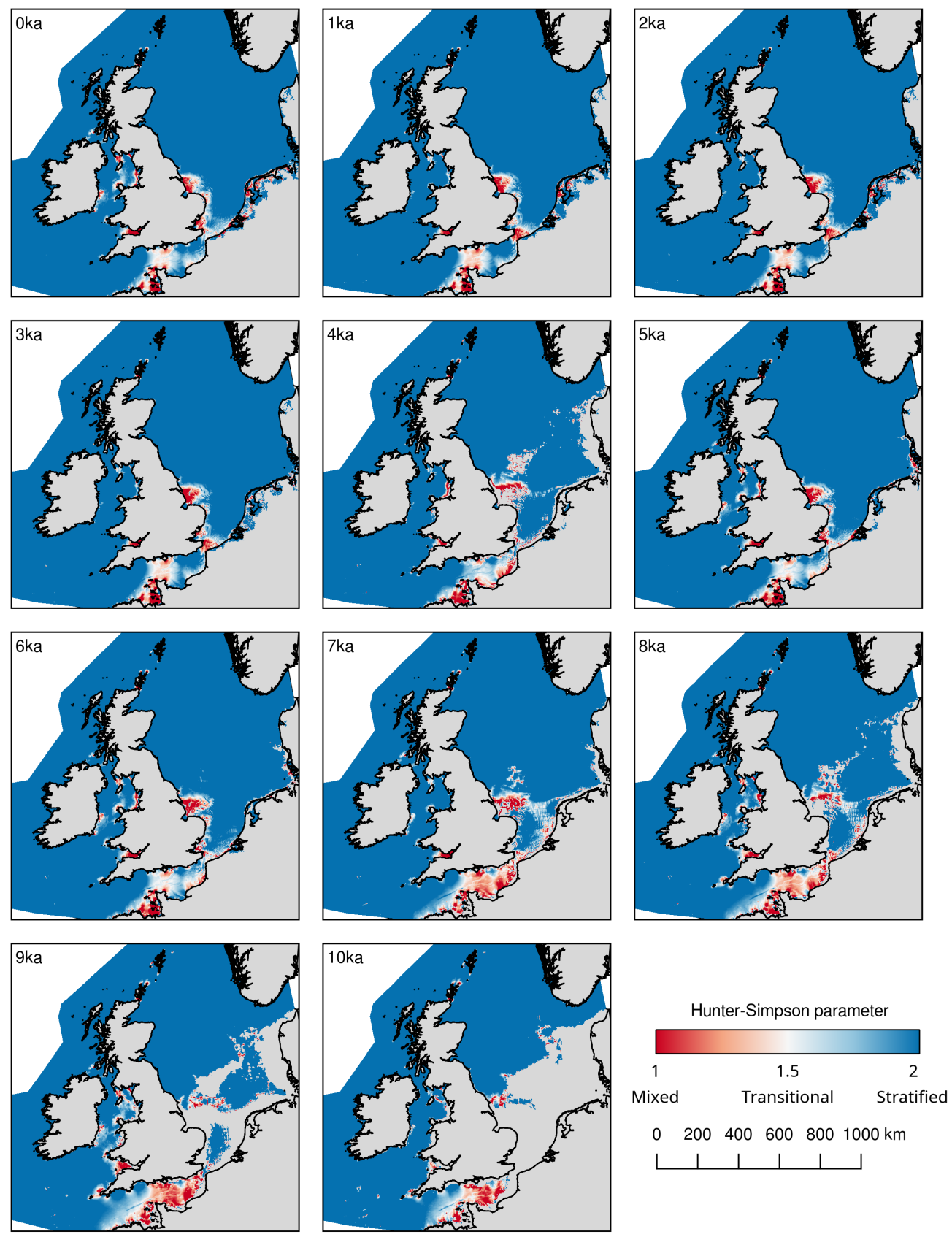

Figure 7. Estimates of the Hunter-Simpson parameter over the last 10,000 years. Blue colours show summer stratification and red show mixed regions. The transition through white colours shows the location of tidal mixing fronts. Grey shading indicates land and the modern coastline is shown in a think black line. 

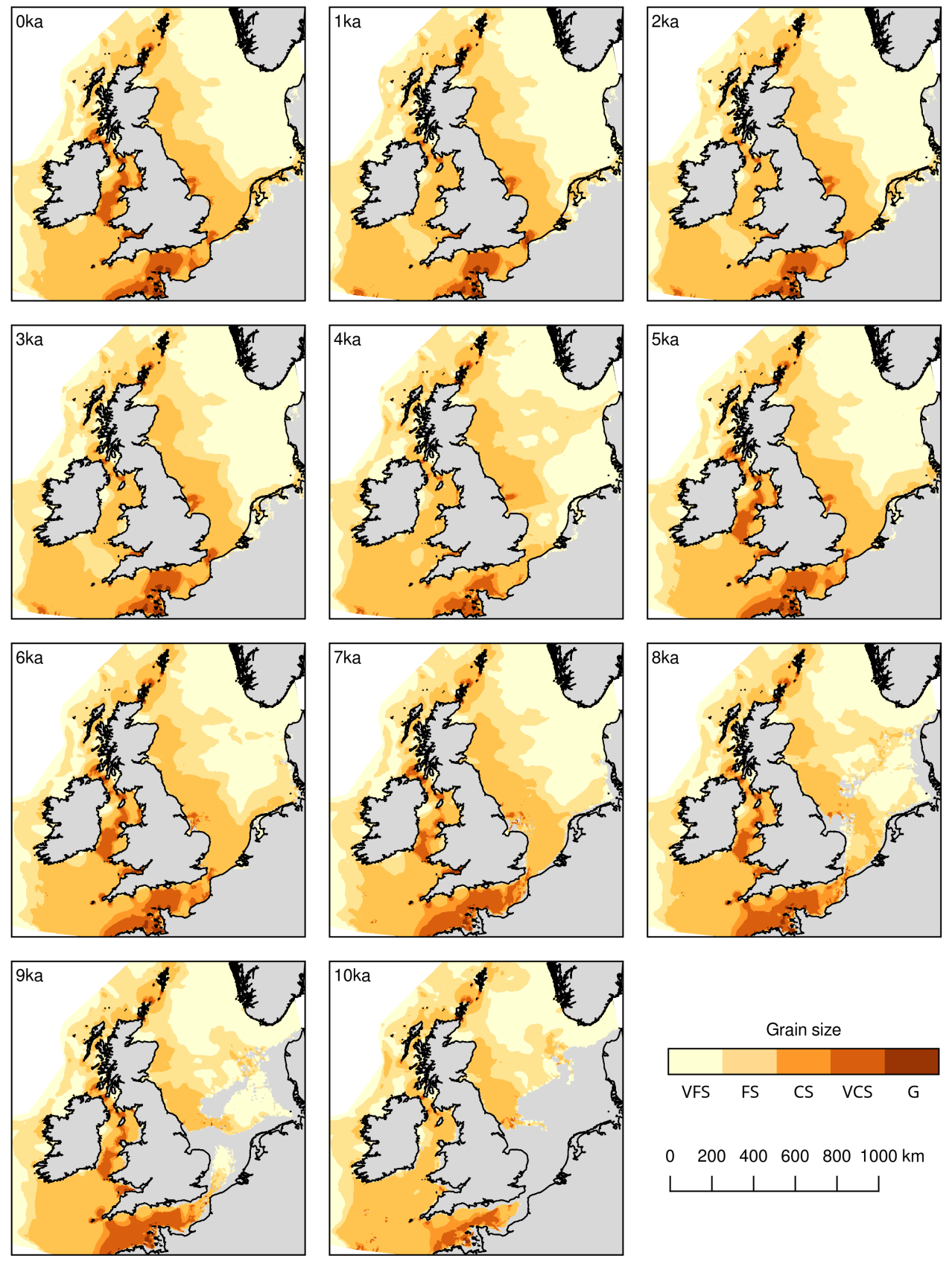

$0 \quad 2004006008001000 \mathrm{~km}$

Figure 8. Sediment grain size derived from maximum bed shear stress predicted from the tidal model corrected using the method detailed in Ward et al. (2015). Grey shading indicates land and the modern coastline is shown in a think black line. 